\title{
Online activity with metacognitive tool for the study of Vertebrate Biology in higher education
}

\author{
${ }^{1}$ Caroline Medeiros Martins de Almeida, ${ }^{2}$ Paulo Tadeu Campos Lopes and ${ }^{3}$ Maria João Santos \\ ${ }^{1}$ Universidade Luterana do Brasil, Programa de Pós-graduação em Ensino de Ciências e Matemática, Avenida Farroupilha, 8001, Bairro S. José, Canoas, RS, \\ Brasil. \\ ${ }^{2}$ Universidade Luterana do Brasil, Programa de Pós-graduação em Ensino de Ciências e Matemática, Avenida Farroupilha, 8001, Bairro S. José, Canoas, RS, \\ Brasil \\ ${ }^{3}$ Universidade do Porto, Departamento de Biologia, Faculdade de Ciências, Rua do Campo Alegre 1021/1055, 4169-007 Porto, Portugal
}

Correspondence Author: Caroline Medeiros Martins de Almeida, Universidade Luterana do Brasil, Programa de Pós-graduação em Ensino de Ciências e Matemática, Avenida Farroupilha, 8001, Bairro S. José, Canoas, RS, Brasil

E-mail: bio_logial@hotmail.com

Received date: 12 August 2018, Accepted date: 15 November 2018, Online date: 27 November 2018

Copyright: () 2018 Caroline Medeiros Martins de Almeida,et al, This is an open-access article distributed under the terms of the Creative Commons Attribution License, which permits unrestricted use, distribution, and reproduction in any medium, provided the original author and source are credited.

\begin{abstract}
The objective of this work was to construct, implement and analyze the effect of an online activity with a metacognitive tool, in the teaching and learning process in the integument content. The study material on tegument content was created on the Wiki (a website with an easy-to-edit code that allows text, links and images to be used without the need to learn programming codes, such as HTML), and allows the student access content from anywhere using the internet, through smartphone, tablet or notebook. The research involved 33 students of the Biology course of a Portuguese public university. The study material was elaborated in topics to facilitate the apprehension of the concepts. The activity was applied in two ways: at distance and face-to-face. To evaluate the acquisition of the content, we used the metacognitive tool conceptual maps, and the evaluation of the satisfaction of performing the activity was verified through the analysis of a questionnaire. The conceptual maps were analyzed through four categories: structure, hierarchy, links between propositions and concepts present on the map. The maps were classified in fully present dimension, dimension partially present and dimension absent. The questionnaire were analyzed through descriptive statistics. In the analysis of the results, we realized that online activity can be used to assist students in the teaching and learning process, since it can stimulate students and it can promote learning, and conceptual maps can support the construction of knowledge, producing many metacognitive gains, since students need to select relevant content information and organize information. In the evaluation of the activity, the great majority indicated that they feel comfortable with the use of the digital technologies in the classes. Understand the importance of exploring different ways of enhancing the teaching and learning process in higher education, in which the teacher can take advantage of the potential of digital media in his / her classes and mobilize diverse skills that are crucial for students' scientific education.
\end{abstract}

Key words: Online education; metacognition; higher education; conceptual maps; digital technologies

\section{INTRODUCTION}

The use of digital technologies in the educational system has greatly influenced teaching and learning practices, making technological learning one of the most significant challenges of the 21st century (Salmon, 2005). Research on the use of digital technologies in higher education has increased significantly in recent years (Kortemeyer 2016; Rienties et al., 2016; Faber et al., 2017), as well as their impact on teaching and learning processes (Casquero et al., 2016; Williamson et al., 2016; García-Pérez et al., 2016).

For Huffaker and Calvert (2003) a well-designed digital learning environment is useful for students to learn how to make decisions by experimenting with a series of metacognitive scaffolding processes. In this context, to organize knowledge, conceptual maps appear as an interesting metacognitive tool to focus the attention of the student in order to achieve higher order thinking skills (Chevron, 2014). François et al., (2018) explain that "empirical data on learners' conceptual progression is required to design curricula and guide students".

Thus, with digital learning tools, such as mobile devices or individualized online learning environments, students can practice tasks tailored to their learning needs (Faber, 2017). Therefore, it is important to study the effects of digital learning tools, and how they can be better implemented in order to contribute to the improvement of teaching and learning processes, since the use of these tools in education is increasing rapidly (De Witte et al., 2015).

Thus, thinking about modernizing and facilitating the teaching of the discipline of Biology of Vertebrate in Higher Education, this article addressed the key question: how the use of an online activity and metacognitive tool can help in the teaching and learning process in a content of the subject of Biology of Vertebrate? In this context, the objective of this work was to construct, implement and analyse the effect of an online activity with a metacognitive tool, in the teaching and learning processes in the integument content. 
Citation: de Almeida, C. M. M., et al., Online activity with metacognitive tool for the study of Vertebrate Biology in higher education, Australian Journal of Basic and Applied Sciences. 12(11): 13-18. DOI: 10.22587/ajbas.2018.12.11.4

\section{THEORETICAL FRAMEWORK}

It can not be disregarded that today's students have been born connected to the computer, the internet and mobile devices, such as smartphones and tablets, as they are part of the generation of digital natives (Prenski, 2001). Nowadays, universities are almost fully occupied by students of Generation Y, possessing radically new learning styles, which can only be involved in the classroom through new teaching strategies and learning spaces (Stenberg, 2012).

Given these data, higher education institutions are being challenged to adopt innovative educational practices that will increase students' learning and success, particularly in the areas of science and mathematics (Spellings, 2006). Therefore, with the use of technology it is observed that the role of the teacher gains a new meaning, which is precisely to create conditions for students to engage in learning activities (Costa and Lopes, 2016).

Virtual empathy is a key competency for the promotion of learning processes in virtual environments (Garcia-Pérez et al., 2016). For Rhema and Miliszewska (2010) e-learning is an ideal learning environment because it uses modern means to integrate digital technologies with the curriculum. It is also a style of learning that can completely reflect the main role of the students to fully reform the structure of traditional teaching and the essence of education, and to train a large number of high-quality students. On the other hand, for Acharya and Sinha (2016) a major disadvantage of web-based learning systems is the lack of face-to-face interaction between students and teacher, so in this context educators should look for other ways to achieve this goal.

In their studies, Marqués and Pelta (2017) used a computer system for teaching and learning psychology topics, and to verify what is the influence of conceptual maps on the student performance. The research was carried out in two schools in Madrid, with students with an average age of 17 years. The computer system was called PSICO-A and was based on many pedagogical influences such as conceptual maps, effective feedback, simulations, digital games, and metacognition. The authors concluded that using the PSICO-A system, through the analysis of the students' conceptual maps, the map design served as "advanced organizers" and there was a significant improvement in the performance of the students who constructed the conceptual maps by computer in comparison with those who built by hand, with paper and a pen.

Acharya and Sinha (2016) in their work proposed a method for the development of conceptual map in a web-based environment to identify concepts in which a student is deficient after learning using traditional methods. Their study revealed that using the concept maps shown to have a positive impact on the proposed learning method.

El-Hussein and Cronje (2010) suggest that m-learning has the potential to become the most effective means of delivering didactic material in higher education. Metacognitive administration includes the application of visualization tools to provide students with structural support to experience the decisionmaking process, and to make revisions of their decisions in electronic learning contexts (Chiu, Chen and Linn 2013).

E-learning is a tool used to transfer teaching or programs through electronic devices such as computer, mobile phone, i-pads, tablets, etc. (Venkataraman and Sivakumar, 2015). Cloud-based storage, interactive interfaces, and mobile applications are the main features that currently support mobile learning (m-learning) (Lin et al. 2014). Thus, m-learning is a contemporary form of flexible learning, which can complement and enhance current learning models (Motiwalla 2007).

Metacognition is a complex concept that refers to the "knowledge on knowledge" that students can develop during the process of acquiring new information (White and Fredericksen, 2005). Flavell (1979) described the term metacognition to label learning on learning, using examples such as: learning to plan, monitoring success, correcting mistakes, etc. For Kuhn (2000) metacognition concerns cognition that reflects, monitors or regulates first order cognition. For the author, metacognition can be divided into metacognitive knowledge (knowledge on declarative knowledge) and metacognitive control (knowledge on strategies and their actual uses). Moreover, we can consider, as Flavell (1987) that metacognitive knowledge and metacognitive experiences are interconnected, as far as knowledge allows experience interpretation and take action on them. These, by their turn, contribute to the development and modification of this knowledge.

Kipnis and Holfstein (2008) comment that the development of metacognitive competences is a desired result in scientific education because it promotes meaningful learning, autonomy and self-regulation. Self-regulation refers to an active and constructive process in which students set goals, monitor and evaluate their cognition, affection, and behaviour (Pintrich, 2000). For Vrugt and Oort (2008) self-regulation is an important aspect of student learning and academic performance. Thus, metacognition and self-regulation are deeper learning concepts.

In this context, conceptual maps are considered metacognitive tools that can provide the student with the opportunity to see new records of events or objects, to reformulate the meanings for the concept of words or symbols and to form new meaningful proposals with relevant elements in the cognitive structure of students (Novak, 2002). For Novak and Cañas (2008), conceptual maps are not only a powerful tool for capturing or representing individuals' knowledge, but it is also a powerful tool for creating new knowledge.

The conceptual maps were developed in 1972 in the course of Novak's research program at Cornell University, where he tryed to follow and understand the changes in children's knowledge (Novak and Musonda, 1991). Researchers in Novak's group sought to represent knowledge as a hierarchical structure of concepts and propositions, a form they called a conceptual map (Cañas and Novak, 2006).

Novak (2002) conceptualizes conceptual map as a tool of representation of knowledge showing concepts and explicit propositions forming a hierarchical structure.

Novak and Cañas (2008) define concept as a perceived regularity in events or objects, or records of events or objects, designated by a label, the label for most concepts is a word, although sometimes it can use symbols, and sometimes more than one word. Propositions are statements about some object or event in the universe, whether of natural or constructed origin, containing two or more connected concepts using connecting words or phrases to form a meaningful statement (Novak and Cañas, 2008). Thus, propositions are the building blocks for knowledge in any domain, and it is very important to have connecting words in the lines that link the concepts in order to form explicit propositional statements (Novak, 1990).

The main objective of the conceptual map is to be a tool that allows one or more person to explicitly represent their understanding of a knowledge domain (Cañas and Novak, 2006).

The conceptual maps have several functions, being a learning tool and also an evaluation tool, thus encouraging students to use learning patterns in a meaningful way (Mintzes et al., 2000; Novak 1990). Conceptual maps are also effective in identifying valid and invalid ideas by students (Novak and Cañas, 2008), and one of the reasons why conceptual maps help to facilitate learning is that they serve as a kind of model or scaffold to help to organize knowledge and structure it (Novak and Wandersee, 1991).

There are today, many different applications for what we call conceptual maps, and many of these applications are substantially different from what was the use when this tool was first developed in 1972. The advancement of digital technology and the development of the Internet have given new ways of using of this tool, thus it would be useful to re-examine the fundamentals for this tool and discuss implications for current and future applications (Cañas and Novak, 2006). The conceptual map have two goals: to reflect the conceptual structure of the content that is being diagrammed, and to obtain evidence of learning, evaluating it (Novak, 2002). Thus, the use of conceptual maps can occur in two perspectives: one as a representation of knowledge, which Novak (2002) defines as a metacognitive tool, showing explicit concepts and propositions, which form a hierarchical structure; and another in the assessment of knowledge that Schultz (2017) reports being the most popular format for diagnostic assessments, offering the advantage that large numbers of students can be tested and results can be quickly generated and distributed compared to written answers, interviews or open surveys.

\section{METHODOLOGY}

\section{Characterization of the research}

The methodological approach chosen was the case study, which, according to Yin (2013) involves an in-depth study of one or a few objects, in a way that allows its broad and detailed knowledge. It was tied to a pre-experimental design because it involves a single case, without control (Campbell and Stanley, 2015).

\section{Research subjects}

The research involved thirty three students of the Biology Bachelor, who enrolled the subject of Biology of Vertebrate, from a Portuguese public university. The study was conducted during the second semester of 2017. 
Citation: de Almeida, C. M. M., et al., Online activity with metacognitive tool for the study of Vertebrate Biology in higher education, Australian Journal of Basic and Applied Sciences. 12(11): 13-18. DOI: 10.22587/ajbas.2018.12.11.4

The discipline Biology of Vertebrates is taught by five teachers and has a workload of 48 hours of contact divided into 24 hours of theoretical classes (without mandatory attendance) and 24 hours of practical classes (with mandatory attendance). Theoretical classes do not have a compulsory presence, thus, with just over a third of the students enrolled in the course attending classes regularly. Practical classes are mandatory. The attendance of the students is quite high, since students can have a maximum of three absences per semester, without losing the frequency of the discipline.

The aim of the course is to show the students the animal biology, its diversity, its main characteristics, its development and its reproduction. In the Biology of Vertebrates, in the theoretical part, the discipline is taught by comparative anatomy, where each organ system is described and the common and distinct structures in each taxonomic group are compared. In the practical classes students study the Vertebrates by taxonomic groups and along the evolutionary scale. This is a basic discipline, of the Bachelor Degree in Biology, and so it is taught in its first year.

\section{Construction and description of the online activity}

The online activity was designed to support the study of integument content, since students had already studied this content in a traditional way. Traditional education, according to Costa et al., (2017) is one that occurs in the classroom, and is commonly centred on the role of the teacher as transmitter of knowledge. For the development of the online activity, a study material was elaborated and a lesson script was created with every steps of the activities.

The study material on tegument content was created on the Wiki (a website with an easy-to-edit code that allows text, links and images to be used without the need to learn programming codes, such as HTML), and allows the student access content from anywhere using the internet, through smartphone, tablet or notebook.

The study material on tegument content was created through textbooks supporting subject from authors Kardong (2015) and Kent and Carr (2001). The activity contained an explanatory text in topics, with illustrative figures, digital games (created through the GoConqr platform, the game chosen was the flash cards), a questionnaire with review questions (created using the Google Forms, available in Google Drive), an evaluation activity consisting of a conceptual map that shown what the students knew about the content studied, answering the question "How is the Vertebrate Tegument?"), and an activity evaluation questionnaire (also created using Google Forms).

The lesson script with a step-by-step of how to carry out the activity online included: the activity's electronic address, the description of the order to carry out the activity, and the explanation what is a conceptual map with an example.

\section{Application of the instrument}

The instrument was applied in two phases: phase 1 at distance, and phase 2 - face-to-face. Phase 2 was chosen because there was not many students who accessed the study material at distance.

Phase 1- Application of the online activity at distance: at the end of a theoretical class, the class script was delivered with the step by step instruction of how to carry out the activity, and was given an explanation of what is a conceptual map and how to do it. Since not all students were present in that day, the class script was also emailed to the class, so all students would be able to perform the activity. It was given a one-week period to students for accessing the study material and performing the evaluative activity. The conceptual maps, which were the evaluative activity, could be done in any program or by hand and sent by e-mail. The software suggested were Lucid chart, Cmap Tools or PowerPoint.

Phase 2- Implementation of on-line activity at face-to-face: part of a practical class of the discipline of Vertebrate Biology and a computer room were reserved for two afternoons, and students were invited to participate in the online activity. These students were guided to a computer room at the university, and received the class script with the step-by-step activities. The activity was carried out in an individual way, in which the students studied on the subject through the available study material and carried out the evaluation activity (conceptual map). It was given a two hours period to students for accessing the study material and performing the evaluative activity. For the good development of the conceptual map, a short explanation was made about the concept of conceptual maps, and how to draw them. The maps were made by hand, due to short time available for the activity.

\section{Collection and analysis of data}

After the application of the instrument, the concepts learned by the students were reviewed through the analysis of the conceptual maps, and the analysis of the evaluation of the activity through the questionnaire.

In order to analyse the conceptual maps produced by students we investigated four categories according to several authors (Novak and Gowin 1984; Novak 2002; Lachner, et al., 2017; Marques and Pelta 2017): A - structure (if the map is structured with the connectors); B - hierarchy (arrangement of concepts, from more general to more specific); C - links between propositions (existence of cross-links between distinct branches); D - concepts present on the map (if it contains the main domain concepts relevant to the content). The maps were classified by numbers: (1) fully present dimension (when structured according to categ ory specifications); (0.5) dimension partially present (when structured according to only partial category specifications); (0) dimension absent (when they did not meet the specifications of the category).

Regarding the activity evaluation questionnaire, the students' answers were analysed based on descriptive statistics tools.

\section{RESULTS AND DISCUSSION}

We invited the Biology undergraduates students attending the Biology of Vertebrate course to perform the online activity, of which five participated in a distance way, and twenty eight participated in the face-to-face way. For Moon and Kim (2001), the external factors that affect the acceptance of a new technology vary from case to case, depending on the situation, users and their technological characteristics.

\section{Distance activity}

In the activity at distance we obtained a very low participation of the students, only five students. Thus, these data led us to ask: Why only five students performed the activity? What would be their possible cognitive characteristics that made them more able to perform the activities?

Iqbal and Bhatti (2017) report that students with self-management skills demonstrated better results in an online learning setting. In addition, it is also observed in previous research that individuals with higher self-discipline skills can adopt m-learning much faster than others (Wang et al., 2009).

The students who participated in the activity at distance made 5 conceptual maps were analysed separately, as shown in (Table 1).

Table 1 - Analysis of the categories used to evaluate the conceptual maps of students, which were enrolled in the activity at distance.

\begin{tabular}{|l|l|l|l|l|}
\hline $\begin{array}{l}\text { Category / } \\
\text { Dimension }\end{array}$ & A (structure) & B (hierarchy) & C (links between propositions) & D (concepts) \\
\hline 1 (present) & $80 \%$ & $80 \%$ & $60 \%$ & $80 \%$ \\
\hline 0,5 (partially present) & $20 \%$ & $20 \%$ & $40 \%$ & $20 \%$ \\
\hline 0 (absent) & $0 \%$ & $0 \%$ & $0 \%$ & $0 \%$ \\
\hline
\end{tabular}

In category $\mathrm{A}, 80 \%$ of the conceptual maps presented a totally present dimension (1), since they were structured with connectors between the concepts. Concept mapping organizes information, themes or their relationships visually, taking into account the integrity and logic of the thought process (Yue et al., 2017). It is very important to have connecting words in the lines that link concepts in order to form explicit propositional statements (Novak, 1990).

In category B, $80 \%$ of the conceptual maps presented a totally present dimension (1), since they expressed a correct hierarchy. For Péladeau et al., (2017) conceptual maps depend on an ascending process of hierarchical agglomeration, whereby items are grouped gradually into one item or proposition at a time, until all items form a single group. 
Citation: de Almeida, C. M. M., et al., Online activity with metacognitive tool for the study of Vertebrate Biology in higher education, Australian Journal of Basic and Applied Sciences. 12(11): 13-18. DOI: 10.22587/ajbas.2018.12.11.4

In category $\mathrm{C}, 60 \%$ of the maps had a totally present size (1), since they had organized associations between distinct branches. According to Novak and Cañas (2008) in creating new knowledge, cross-links often represent creative leaps and help see how a concept in one domain of knowledge represented in the map is related to a concept in another domain shown on the map.

In category $\mathrm{D}, 80 \%$ of the maps had a fully present dimension (1), containing the main domain concepts relevant to the content. Conceptual maps are effective in identifying valid and invalid ideas (concepts) carried out by students (Novak and Cañas, 2008).

The conceptual maps of the students who performed the activity at a distance presented a high level of complexity. It is important to note that there was a substantial dedication in the construction of the conceptual maps, since no map had a totally absent dimension.

Face-to-face activity

Twenty-eight students participated in the study, making twenty eight conceptual maps that were analysed separately, as shown in Table 2.

Table 2- Analysis of the categories used to evaluate the conceptual maps of the students enrolled at face-to-face activity

\begin{tabular}{|l|l|l|l|l|}
\hline $\begin{array}{l}\text { Category / } \\
\text { Dimension }\end{array}$ & A (structure) & B (hierarchy) & C (links between propositions) & D (concepts) \\
\hline 1 (present) & $25 \%$ & $32.1 \%$ & $3.6 \%$ & $39.3 \%$ \\
\hline 0.5 (partially present) & $57.1 \%$ & $50 \%$ & $39.3 \%$ & $67.3 \%$ \\
\hline 0 (absent) & $17.9 \%$ & $17.9 \%$ & $57.1 \%$ & $0 \%$ \\
\hline
\end{tabular}

In category A, only $25 \%$ of the maps had a totally present dimension (1), since they were structured with the connectors between the concepts. According to Novak (2002) conceptual maps that do not specify the connections between concepts fail, since they do not form propositions that are the essential elements to represent knowledge.

In category $\mathrm{B}, 32.1 \%$ of the maps presented a totally present dimension (1), since they expressed hierarchy, and showed levels of progression between the concepts. The hierarchy is important to indicate which concepts are more inclusive, or more salient in a given context, in which the knowledge structure is applied (Novak, 2002).

In category C, $3.6 \%$ of the maps had a totally present dimension (1), since they had associations organized between distinct branches. Péladeau et al., (2017) report that a well-known deficiency of such an approach is that some items that were aggregated at an early stage may be associated with additional items that are rarely paired with them, as far as groups become larger,.

In category D, $39.3 \%$ of the maps presented a totally present dimension (1), containing the main domain concepts relevant to the content. The concepts to be included provide the teacher with an insight into which concepts the student had a good understanding of, and which he had problems integrating into the conceptual map, indicating in this case little or no understanding of these concepts (Novak and Cañas, 2008).

The conceptual maps of face-to-face activity presented a lower level of complexity, some maps were incomplete, and some maps present a totally absent dimension. For Novak and Cañas, (2008) while conceptual maps can help in the process of knowledge acquisition, students also need to be taught about brain mechanisms of knowledge organization (metacognition and knowledge regulation), and this instruction can be transmitted through the use of conceptual maps. Berkhout et al., (2017) comment that it would be interesting to gain deeper understanding of how various aspects of the context influence the behaviour of selfregulating students, and how these aspects could be used to reinforce learning behaviour.

In online activities enrolled at distance, the student chooses the place and time to study, and needs to organize his own time, what helps to promote selfregulation learning strategies, which does not occur in a face-to-face class, that the student has a determined time and place to study. For Boekaerts et al., (2001), self-regulation skills are fundamental for students to guide their own progression in the educational scale, to ensure formative continuity, and to effectively learn. Taylor and Littleton-Kearney (2011) support that conceptual mapping as an effective strategy to promote the development of critical thinking. Thus, when students draw their maps and select relevant information from a content, they organize information into coherent representations and integrate relationships between and within the elements producing many metacognitive gains. Our data corroborate those obtained by Lachner et al., (2017) when they comment that the use of conceptual map has shown to support students to develop relevant writing skills. François et al., (2018) comment "learners' diverse and often surprising conceptual paths challenge the view of learning as a linear process".

The conceptual map has been used by many researchers to structure and organize knowledge in online learning systems (Acharya and Sinha, 2016). For Flavell (1979), cognitive regulation shows itself in planning, monitoring, control and evaluation activities, as long as students solve a problem. This same task was made by our students, when they constructed the conceptual maps and answered the focus question.

\section{Evaluation of the online activity}

In the assessment of online activity regarding the level of student satisfaction, $100 \%$ of the students reported having no difficulties accessing the online activity. Once they provide a viable and easy-to-use technological environment, students are likely to engage in technology, potentially resulting in more genuine learning experiences (Lachner et al., 2017).

Regarding the quality of the study material, $52.9 \%$ classified as very good, $29.4 \%$ classified as good, and $17.6 \%$ classified as regular.

When questioned about the use of digital technologies in classrooms, positive (84.9\%) and negative (15.1\%) ideas emerged, from which nine subcategories were proposed: (21.2\%) "very good", (18.2\%) "interesting", (6.1\%) "makes the classes more dynamic", (6.1\%) "useful", (15.1\%) "improves the study", (9.1\%) "didactic and educational", (3\%) "easy accessibility", and only (15.1\%) "did not find it interesting". According to Pillay et al., (2007), computer self-efficacy, technical skills, computer attitude and learning preferences are the key qualities that may explain individual differences in achievement and academic satisfaction in online learning environments.

When questioned whether conceptual maps helped to facilitate learning, positive (88\%) and negative (12\%) ideas emerged, from which seven subcategories were described: (6\%) "interpretation aid", (31\%) "helps to summarize the content", (21\%) "is a good study tool", (9\%) "is practical", and only (6\%) "found the tool unclear" and $(6 \%)$ "did not find it easy".

Faber et al. (2017) comment that with digital learning tools such as mobile devices or individualized online learning environments, students can practice with tasks adapted to their own learning needs.

\section{CONCLUSIONS}

The main objective of this research was to construct, implement and analyse the effect of an online activity with a metacognitive tool in the teaching and learning process, in the integument content. For fulfilling these aims, in the stage of the construction of online activity we do not found many difficulties, because there is a lot of helpful technology. However, the step we considered most delicate (complex, difficult, troubled) was to implement online activity at a distance, because few students accessed the material in this way, leading us to apply the activity also face-to-face.

The adherence of the students at the distance activity diverged from the answers given by the students in the evaluation of the activity, which reported having no difficulties accessing the online activity, and the great majority indicated that they feel comfortable with the use of digital technologies in the classes.

In the analysis of the conceptual maps, their support in the construction of the knowledge was verified, since the students had to select relevant information of the content, to organize information and to integrate relations between and within the elements, producing many metacognitive gains.

Online activity can stimulate students in the construction of knowledge and favour the occurrence of learning. We understand the importance of exploring different ways of enhancing the teaching and learning process in higher education, in which the teacher can take advantage of the potential of digital media in his / 
Citation: de Almeida, C. M. M., et al., Online activity with metacognitive tool for the study of Vertebrate Biology in higher education, Australian Journal of Basic and Applied Sciences. 12(11): 13-18. DOI: 10.22587/ajbas.2018.12.11.4

her classes and mobilize diverse skills that are crucial for students' scientific education. However, it is worth exploring the learning mechanism to develop different applications of digital technologies and metacognitive tools in higher education classes.

The results have important implications for Biology researchers and educators in Higher Education, since the e-learning / m-learning teaching modality can be considered as a complementary form of study, and may help to enhance teaching. Therefore, this study may contribute to research on teaching and learning based on digital technologies and metacognitive tools.

The study reported in this article shows how digital technologies can be used to support students in the teaching and learning process in disciplines with very large classes and with very extensive content. Thus, it seems to us very important to change the attitude of students in the learning process. Our approach to online activity and use of conceptual map proved to be easy to implement, and feasible, to assist in the teaching and learning process.

We noticed the need for some future adjustments of methodology and online activity to help to increase the acceptance of technology in Biology classes in higher education in Portugal. In anear future we want to better explore strategies to support and stimulate metacognition and self-regulated learning of students.

\section{ACKNOWLEDGMENTS AND SUPPORTS}

This study was financed in part by the Coordenação de Aperfeiçoamento de Pessoal de Nível Superior - Brasil (CAPES) - Finance Code 001.

\section{REFERENCES}

Acharya, A., and D. Sinha., 2016. An Intelligent Web-Based System for Diagnosing Student Learning Problems Using Concept Maps. Journal of Educational Computing Research, 55(3):323-345.

Altrichter, H., S. Kemmis, R. McTaggart, and O, Zuber-Skerritt., 2002. The concept of action research. The learning organization, 9(3): 125-131.

Ames, C., 1992. Classrooms: goals, structures and student motivation. Journal of Educational Psychology, 84:261-271.

Berkhout, J. J., P. W. Teunissen, E. Helmich, J. van Exel, C. P. van der Vleuten, and , D. A. Jaarsma., 2017. Patterns in clinical students' self-regulated learning behavior: a Q-methodology study. Advances in Health Sciences Education. 22(1):105-121.

Boekaerts, M., P. R.Pintrich, and M. Zeidner. (Eds.)., 2000. Handbook of self-regulation. San Diego: Academic.

Campbell, D. T. and J. C. Stanley., 2015. Experimental and quasi-experimental designs for research. Ravenio Books.

Cañas, A. J. and J. D. Novak., 2006. Re-examining the foundations for effective use of concept maps. In Concept maps: theory, methodology, technology. Proceedings of the second international conference on concept mapping. 1:494-502.

Casquero, O., R. Ovelar, J. Romo, M. Benito, and M. Alberdi., 2016. Students' personal networks in virtual and personal learning environments: a case study in higher education using learning analytics approach. Interactive Learning Environments, 24(1):49-67.

Chevron, M. P., 2014. A metacognitive tool: Theoretical and operational analysis of skills exercised in structured concept maps. Perspectives in Science, 2(1): 4654.

Chiu, J. L., J. K. Chen, and M. C. Linn., 2013. Overcoming descriptive clarity by encouraging metacognition in the web-based inquiry science environment. In R. Azevedo \& V. Aleven (Eds.), International handbook of metacognition and learning technologies. 517-531. Springer New York.

Costa, R. D. A., and P. T. C. Lopes., 2016. M-learninf: development and evaluation of an application for the teaching and learning of human anatomy. Interciencia. 41(7):482-487.

Costa, V. R., A. H. Lopes, A. J. Sarri,Z. C. Benedetti, and C. Z de Oliveira., 2017. Oncology E-Learning for Undergraduate. A Prospective Randomized Controlled Trial. Journal of cancer education: the official journal of the American Association for Cancer Education. 32(2):344-351.

De Witte, K., C. Haelermans, and N. Rogge., 2015. The effectiveness of a computer-assisted math learning program. Journal of Computer Assisted Learning, 31(4):314-329.

El-Hussein, M. O. M., and J. C. Cronje., 2010. Defining mobile learning in the higher education landscape. Educational Technology \& Society. 13(3):12-21.

Faber, J. M., H. Luyten, and A. J. Visscher., 2017. The effects of a digital formative assessment tool on mathematics achievement and student motivation: Results of a randomized experiment. Computers \& education. 106:83-96.

Flavell, J. H., 1979. Metacognition and cognitive monitoring: a new area of cognitive developmental inquiry. American Psychologist. 34(10):906-911.

Flavell, J. H., 1987. Speculation about the nature and development of metacognition. In: F. E. Wernert and R. H. Kluwe (Eds.), Metacognition, Motivation and Understanding. Hillsdale, NJ: Lawrence Erlbaum Associates.

García-Pérez, R., J. M. Santos-Delgado, and O. Buzón-García., 2016. Virtual empathy as digital competence in education 3.0. International Journal of Educational Technology in Higher Education. 13(1):30.

Huffaker, D. A., and S. L. Calvert., 2003. The new science of learning: Active learning, metacognition, and transfer of knowledge in e-learning applications. Journal of Educational Computing Research. 29(3):325-334.

Iqbal, S., and Z. B. Bhatti., 2017. What drives m-learning? An empirical investigation of university student perceptions in Pakistan. Higher Education Research \& Development. 36(4):730-746.

Kardong, K. V., 2015. Vertebrates comparative anatomy, function, evolution. 7th Edition. Mc Graw Hill. New York.

Kent G. C., and R. K. Carr., 2001. Comparative anatomy of the Vertebrates. 9th Edition. Mc Graw Hill. New York.

Kipnis, M., and A. Hofstein., 2008. The inquiry laboratory as a source for development of metacognitive skills. International Journal of Science and Mathematics Education. 6(3):601-627.

Kortemeyer, G., 2016. Work Habits of Students in Traditional and Online Sections of an Introductory Physics Course: A Case Study. Journal of Science Education and Technology. 25(5):697-703.

Kuhn, D., 2000. Metacognitive development. Current Directions in Psychological Science. 9:178-181.

Lachner, A., C. Burkhart, and M. Nückles., 2017. Formative computer-based feedback in the university classroom: Specific concept maps scaffold students' writing. Computers in Human Behavior. 72:459-469.

Lin, Y., M. Wen, M. Jou, and D. Wu., 2014. A cloud-based learning environment for developing student reflection abilities. Computers in Human Behavior. 32:244 -252.

Lombard, F., M. Merminod, V. Widmer, and D. K. Schneider., 2018. A method to reveal fine-grained and diverse conceptual progressions during learning, Journal of Biological Education. 52 (1):101-112.

Marqués, J. G., C. Pelta., 2017. Concept maps and simulations in a computer system for learning Psychology. European Journal of Education and Psycholog. 10(1):33-39.

Mintzes, J. J., J. H. Wandersee, J. D. Novak., 2000. Assessing science understanding: A human constructivist view. San Diego: Academic.

Moon, J., and Y. Kim., 2001. Extending the TAM for a world-wide-web context. Information \& Management. 38(4):217-230.

Motiwalla, L. F., 2007. Mobile learning: A framework and evaluation. Computers \& education. 49(3):581-596.

Novak, J. D., 1990. Concept maps and Vee diagrams: Two metacognitive tools to facilitate meaningful learning. Instructional science. 19(1):29-52.

Novak, J. D. 1991. A twelve-year longitudinal study of science concept learning. American Educational Research Journal. 28 (1);117-153.

Novak, J. D., 2002. Meaningful learning: The essential factor for conceptual change in limited or inappropriate propositional hierarchies leading to empowerment of learners. Science Education. 86(4):548-571.

Novak, J. D., and A. J. Cañas., 2008. The theory underlying concept maps and how to construct and use them. Flórida, 2008. Disponível em: < http://cmap.ihmc.us/docs/theory-of-concept-maps >. Acesso em: 5.2016.

Novak, J. D., D. B. Gowin., 1984. Learning how to learn. New York: Cambridge University Press. 
Novak, J. D., and D. Musonda., 1991. A twelve-year longitudinal study of science concept learning. American Educational Research Journal. 28 (1):117-153.

Novak, J. D., and J. Wandersee., 1991. Coeditors, special issue on concept mapping. Journal of Research in Science Teaching, 28(10).

Péladeau, N., C. Dagenais, V. Ridde., 2017. Concept mapping internal validity: A case of misconceived mapping?. Evaluation and Program Planning. 62:56-63.

Pillay, H., K. Irving, and M. Tones., 2007. Validation of the diagnostic tool for assessing tertiary stu- dents' readiness for online learning. High Education Research \& Development. 26(2):217-234.

Pintrich, P. R., 2000. The role of goal orientation in self-regulated learning. In M. Boekaerts, P. R. Pintrich, and M. Zeidner (Eds.), Handbook of self-regulation (451-502). San Diego: Academic Press.

Prensky, M. 2001., Digital natives, digital immigrants part 1. On the horizon. 9(5):1-6.

Rienties, B., B. Giesbers, S. Lygo-Baker, H. W. S Ma, and R. Rees., 2016. Why some teachers easily learn to use a new virtual learning environment: a technology acceptance perspective. Interactive Learning Environments. 24(3):539-552.

Rhema, A., and I. Miliszewska., 2010. Towards e-learning in higher education in Libya. Issues in Informing Science and Information Technology. 7(1):423-437.

Salmon, G., 2005. Flying not flapping: a strategic framework for e-learning and pedagogical innovation in higher education institutions. ALT-J. 13(3):201-218.

Schultz, M., G. A. Lawrie, C. H. Bailey, S. B. Bedford, T. R. Dargaville, G. O'Brien, and A. H Wright., 2017. Evaluation of diagnostic tools that tertiary teachers can apply to profile their students' conceptions. International Journal of Science Education. 39(5):565-586.

Spellings, M., 2006. A test of leadership: charting the future of U.S. higher education. U.S. Department of Education, Washington, DC.

Sternberg, J., 2012. 'It's the end of the university as we know it (and I feel fine)': The generation Y student in higher education discourse. Higher Education Research \& Development. 31(4):571-583.

Taylor, L. A., and M. Littleton-Kearney., 2011. Concept mapping: a distinctive educational approach to foster critical thinking. Nurse Education. 36(2):84-88.

Wang, Y., M. Wu, and H. Wang., 2009. Investigating the determinants and age and gender differences in the acceptance of mobile learning. British Journal of Educational Technology. 40(1):92-118.

White, B., and J. Fredericksen., 2005. A theoretical framework and approach for fostering metacognitive development. Educational Psychologist. 49:211-223.

Williamson, K. C., V. M. Williamson, and S. R. Hinze., 2016. Administering Spatial and Cognitive Instruments In-class and On-line: Are These Equivalent?. Journal of Science Education and Technology. 1(26):12-23.

Wolters, C. A. 2003., Regulation of motivation: evaluating an underemphasized aspect of self-regulated learning. Educational Psychologist. 38:189-205.

Yin, R. K. 2013., Case study research: Design and methods. Sage publications.

Yue, M., M. Zhang, C. Zhang, and C. Jin., 2017. The effectiveness of concept mapping on development of critical thinking in nursing education: A systematic review and meta-analysis. Nurse Education Today. 52:87-94.

Venkataraman, S., and S. Sivakumar. 2015. Engaging students in Group based Learning through e-learning techniques in Higher Education System. International Journal of Emerging Trends in Science and Technology. 2(1):1741-1746.

Vrugt, A., and F. J. Oort., 2008. Metacognition, achievement goals, study strategies and academic achievement: pathways to achievement. Metacognition and learning. 3(2):123-146. 